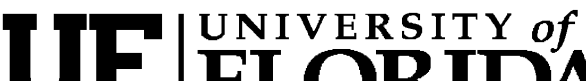 FLORIDA \\ IFAS Extension
}

\section{American Dog Tick, Dermacentor variabilis (Say) (Arachnida: Ixodida: Ixodidae) 1}

\section{Wai-Han Chan and Phillip E. Kaufman² \\ Introduction}

Dermacentor variabilis (Say), also known as the American dog tick or wood tick, is found predominantly in the United States, east of the Rocky Mountains, and as its name suggests, is most commonly found on dogs as an adult. The tick also occurs in certain areas of Canada, Mexico and the Pacific Northwest of the U.S. (Mcnemee et al. 2003). Dermacentor variabilis is a 3-host tick, targeting smaller mammals as a larva and nymph and larger mammals as an adult. Although it is normally found on dogs, this tick will readily attack larger animals, such as cattle, horses, and even humans. The 8-legged adult is a vector of the pathogens causing Rocky Mountain spotted fever (RMSF) and tularemia, and can cause canine tick paralysis. While the American dog tick can be managed without pesticides, when necessary a recommended acaricide is an effective way of eliminating an existing tick infestation near residences.

\section{Distribution}

The American dog tick is widely distributed in the United States east of a line drawn from Montana to South Texas. It is also found in Canada, east of

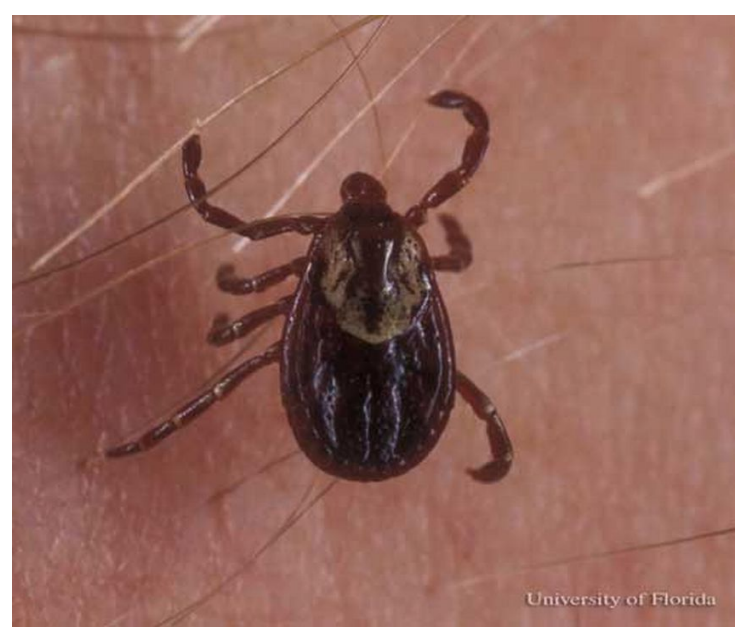

Figure 1. Adult female American dog tick, Dermacentor variabilis (Say). Credits: Lyle J. Buss, University of Florida

Saskatchewan, and in California, west of the Cascade and the Sierra Nevada Mountain ranges. This species is most abundant in the eastern United States from Massachusetts south to Florida but is also common in more central areas of the U.S., including Iowa and Minnesota (Matheson 1950).

It was been suggested that adult ticks move to the edge of the roads and trails in an attempt to find a host, or "quest." Some have hypothesized that because many animals typically follow trails, they

1. This document is EENY-443, one of a series of the Entomology and Nematology Department, Florida Cooperative Extension Service, Institute of Food and Agricultural Sciences, University of Florida. Original publication date November 2008. Visit the EDIS Web Site at http://edis.ifas.ufl.edu. 2. Wai-Han Chan and Phillip E. Kaufman, Department of Entomology and Nematology, University of Florida, Gainesville, FL.

The Institute of Food and Agricultural Sciences (IFAS) is an Equal Opportunity Institution authorized to provide research, educational information and other services only to individuals and institutions that function with non-discrimination with respect to race, creed, color, religion, age, disability, sex, sexual orientation, marital status, national origin, political opinions or affiliations. U.S. Department of Agriculture, Cooperative Extension Service, University of Florida, IFAS, Florida A. \& M. University Cooperative Extension Program, and Boards of County Commissioners Cooperating. Larry Arrington, Dean 
leave an odor that attracts these ticks causing them to move toward and quest alongside trails in attempts to find a host (Mcnemee et al. 2003).

\section{Description}

The 8-legged adult male and female $D$. variabilis ticks are typically brown to reddish-brown in color with gray/silver markings on their scutum (dorsal "shield"). The female will vary in size depending on whether or not it has blood fed. Unfed females are typically $5 \mathrm{~mm}$ long and are slightly larger than males, which are about $3.6 \mathrm{~mm}$ long. Females can be distinguished by a short or small dorsal scutum, right behind the mouthparts while the male scutum covers the majority of its dorsal surface. Blood-fed (engorged) females can enlarge up to $15 \mathrm{~mm}$ long and $10 \mathrm{~mm}$ wide.

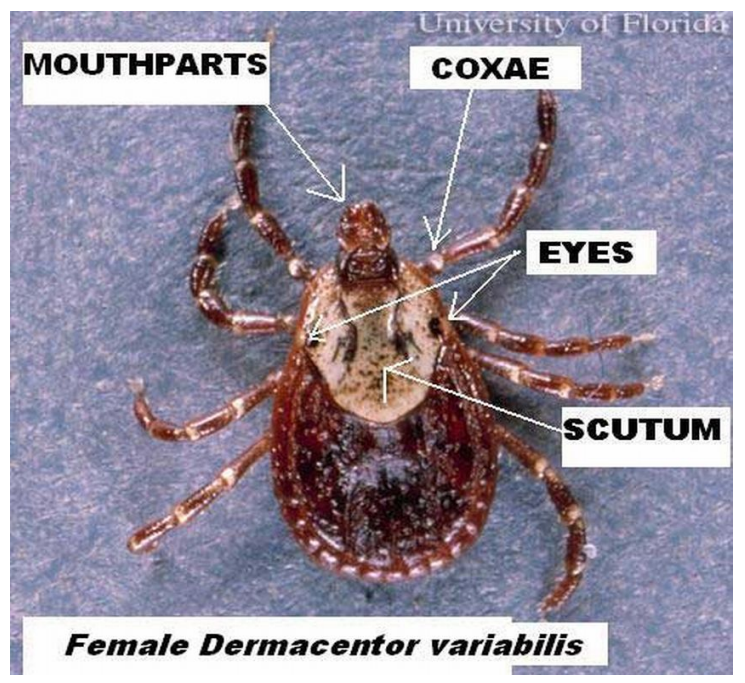

Figure 2. Dorsal view of adult female American dog tick, Dermacentor variabilis (Say), with body parts marked. Credits: J.F. Butler, University of Florida

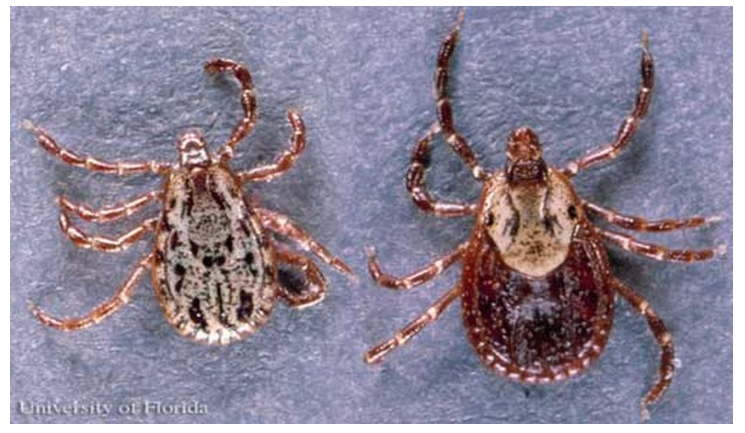

Figure 3. Dorsal view of American dog ticks, Dermacentor variabilis (Say), with male on left, and female on right. Credits: J.F. Butler, University of Florida

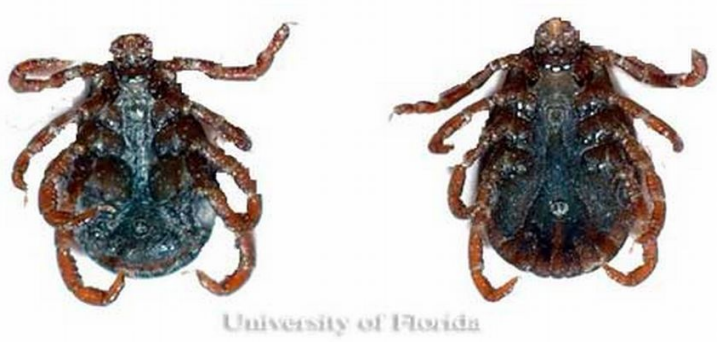

Figure 4. Ventral view of American dog ticks, Dermacentor variabilis (Say), with male on left, and female on right. Credits: K. Wilson, University of Florida

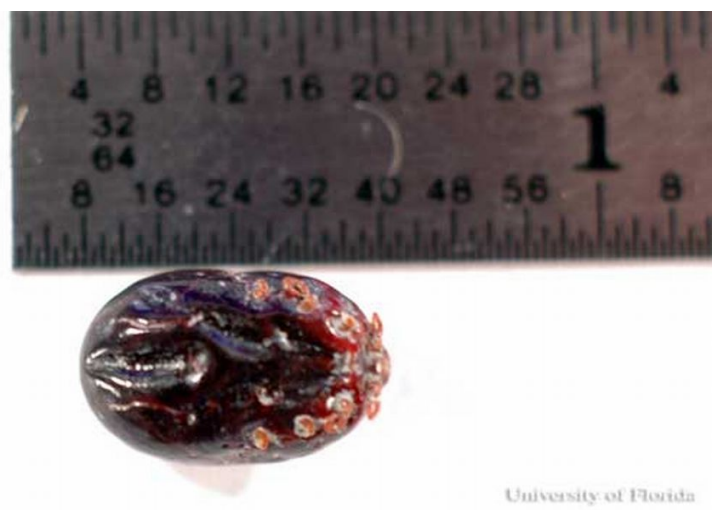

Figure 5. Engorged adult female American dog tick, Dermacentor variabilis (Say). Credits: K. Wilson, University of Florida

The mouthparts and their base, also known as the capitulum, are visible when viewing from above, with the second segment of the palps about as long as it is wide (Smith and Whitman 1992). The anal and genital openings occur on the underside of ticks. Only adults possess genital openings. Posterior to the anus, there is a groove and the spiracular plate is directly behind the fourth coxae (leg attachment segment).

There are two stages of immature ticks: 6-legged larvae and 8-legged nymphs. Larvae are $\sim 0.62 \mathrm{~mm}$ long and are yellow before blood-feeding and gray to black when engorged. Nymphs are about $0.9 \mathrm{~mm}$ long, and a pale, yellow-like brown before blood-feeding and become slate gray when engorged (Smith and Whitman 1992). Both stages of immature tick will have red markings near their eyes and will lack white coloration on the scutum (shield). Nymphs can be distinguished from adults by the lack of a genital opening. 


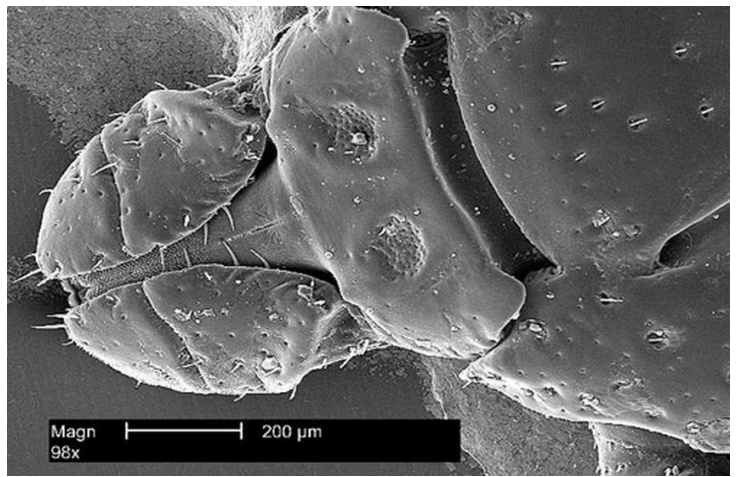

Figure 6. Dorsal view of the head region from the American dog tick, Dermacentor variabilis (Say). For an even closer look at the mouthparts at the left of the image, seen slightly lower than a line drawn through the center of the figure 9. Credits: Janice Carr, Center for Disease Control
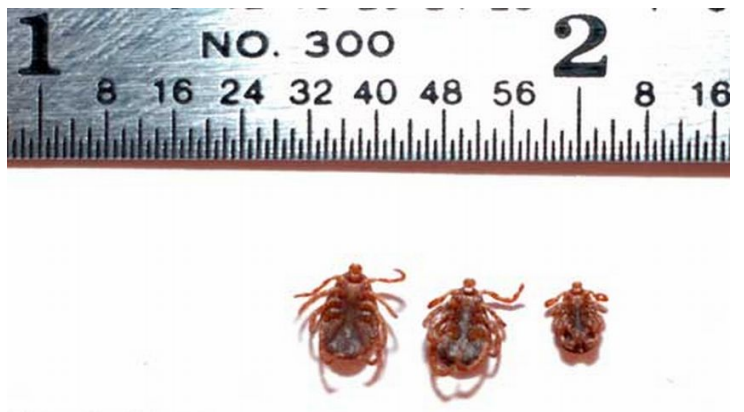

Figure 7. Relative sizes of American dog ticks, Dermacentor variabilis (Say), with male (left), female (center), nymph (right). Credits: K. Wilson, University of Florida

\section{Life Cycle}

Dermacentor variabilis develops from the egg stage, to the 6-legged larva, to the 8-legged nymph, and finally to the adult. The cycle requires a blood meal before progression from larva to nymph, from nymph to adult and by the adult for egg production. This cycle also requires three different hosts and requires at least 54 days to complete, but can take up to two years depending on the host availability, host location and the temperature.

After five to 14 days of blood feeding, a fully engorged female $\mathrm{D}$. variabilis drops from the host. She digests the blood meal and develops her egg clutch over the next four to 10 days. She then lays anywhere from 4,000 to 6,500 eggs on the ground (Matheson 1950). About 26 to 40 days later, depending on the temperature, the eggs hatch into larvae (James et al. 1969).
Stages of Dermacentor variabilis the American Dog Tick

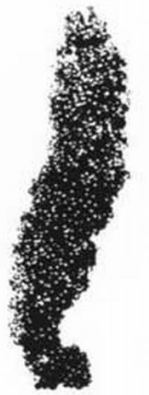

Egg Cluster

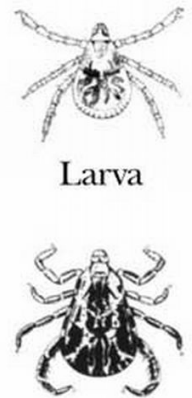

Male

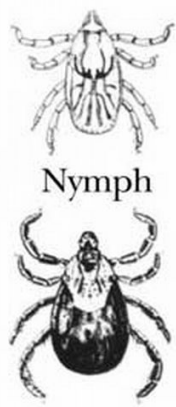

Female
Figure 8. Life cycle of the American dog tick, Dermacentor variabilis (Say). Credits: Center for Disease Control

After hatching, larvae remain on the ground or climb growing vegetation where they wait for small mammals, such as mice, to serve as hosts for their first blood meal. This host location behavior is called questing. Under favorable conditions, larvae can survive up to 11 months without feeding. After contacting and attaching to a host, larvae require from two to 14 days to complete blood feeding. After feeding, larvae detach from their host and fall to the ground where they digest their blood meal and molt into the nymphal stage. This process can take as little as a week, although this period is often prolonged.

Nymphs can survive six months without a blood meal. After successfully questing for their second host, which is normally a slightly larger mammal (such as a raccoon or opossum), the nymphs will blood feed over a three to 10-day period. After engorging, they fall off the host, digest their blood meal and molt into adults. This process can take anywhere from three weeks to several months.

Adults can survive two years without feeding, but readily feed on dogs or other larger animals when available. Questing adult ticks climb onto a grass blade or other low vegetation, cling to it with their third pair of legs, and wave their legs as a potential host approaches. As the hosts brush the vegetation, the ticks grab onto the passing animal. Mating occurs on the host and the female engorges within six to 13 days after which she drops from the host to lay her eggs and then she dies, thus completing the cycle (Matheson 1950). 


\section{Seasonality}

Adult American dog ticks overwinter in the soil and are most active from around mid-April to early September. Larvae are active from about March through July and nymphs are usually found from June to early September (Goddard 1996). In northern areas, such as Massachusetts and Nova Scotia, adults appear from April to August with a peak in May and June (Campbell 1979, McEnroe 1979a). In central latitudes of the U.S., such as Virginia, adults are found to be active from April to September/October with peaks in May and July (Sonenshine and Sout 1971, Carroll and Nichols 1986). In Ohio, adult activity occurred between April and September with a peak in May/June and a second smaller peak in August/September (Conlon and Rockett 1982).

A study done in Lexington, Kentucky, found the duration of D. variabilis' spring activity was related to its overwintering success. This study also concluded that overwintering adult $D$. variabilis ticks remained active throughout the entire season (Burg 2001). This same study reported that adult activity began a week or two earlier than in more northern states, such as Ohio, and a week or two later than in more southern states, such as Georgia. In Georgia, adult ticks are active from late March to August with peaks from early May to late June (Newhouse 1983). While in Florida, adult $D$. variabilis activity occurs from April to July (McEnroe 1979b).

\section{Medical and Veterinary Importance}

The American dog tick is the primary vector for the pathogen causing Rocky Mountain spotted fever (RMSF), although it is also known to transmit the causative agent of tularemia and can cause canine tick paralysis. First discovered in the late 19th century in the Rocky Mountain region, RMSF is more commonly reported in eastern U.S. Rickettsia rickettsii, the causative agent of RMSF, is primarily vectored by $D$. variabilis to dogs and humans following its acquisition from rodents. Overwintering larvae can also acquire RMSF transovarially (mother to egg) yielding RMSF-infected larvae (Piesman and Gage 1996). Because larval and nymphal ticks rarely bite humans, the adult tick is the primary lifestage of concern for humans. In the southeast U.S., peak occurrence of the disease is in July, at or shortly after the peak activity of adult $D$. variabilis.

Rocky Mountain spotted fever is an infectious disease. The rickettsia affect small peripheral blood vessels causing rashes to develop within two to five days. These rashes are known to start in the wrists and ankles and move up to the rest of the body. Because of its direct association with adult $D$. variabilis, RMSF is a seasonal disease, and is more prevalent during the months between April and September. Symptoms usually appear within two to 14 days, with averages of around a week. Fever, nausea, vomiting, diarrhea, headaches, muscle pain and lack or appetite are all symptoms of this disease. Clinical symptoms include elevated liver enzymes, abnormal platelet count, and electrolyte abnormalities (ALDF 2006). Mortality from this disease in humans is 20 to $25 \%$ if untreated and 5\% with appropriate clinical therapy. In order for transmission to occur, however, the tick must be attached for six to eight hours and in some cases transmission requires more than 24 hours (Thorner et al. 1998).

Dermacentor variabilis can also vector Francisella tularensis, the organism causing tularemia. This gram negative coccobacillus (bacteria) also can be transmitted by contact with arthropods including other ticks, deer flies, mosquitoes, fleas, as well as from infected animals (principally rabbits) to hunters and ranchers. However person-to-person contact is rare. Incubation for this disease is usually three to five days but can take up to 21 days for symptoms to appear (CCHDOE 2001). Symptoms of tularemia include chills, fever, prostration, ulceration at the site of the bite, and tender, swollen lymph nodes. If untreated, fatality rates may be as high as 5 to $7 \%$. Tularemia occurs only in the northern hemisphere and most frequently in Scandinavia, North America, Japan, and Russia (Ellis et al. 2002).

Canine tick paralysis can occur due to the feeding of $D$. variabilis. In this case, the tick will attach to the back of the dog's neck, or at the base of the skull, and feed for at least five to six days. It is believed to release a salivary gland protein into the body. Paralytic symptoms then become visible through unsteadiness and loss of reflex actions. If the 
tick is not removed, respiratory failures can be fatal. Such paralysis is not limited to dogs, as it can happen to children as well. Once the tick is properly removed, recovery is usually within one to three days (Schmitt 1969). In the U.S., the fatality rate is about $10 \%$ in the Pacific Northwest, and most of those who die are children (Gregson 1973).

\section{Removal}

Ticks should not be removed by handpicking because infected tick secretions can be transferred from a person's hands to his or her eyes, mucous membranes, mouth, etc. Therefore, forceps should be used when removing a tick (Smith and Whitman 1992). To properly remove a tick, grasp the mouthparts near the attachment site firmly with tweezers. Once the mouthparts are held, the tick should be pulled straight back slowly to ensure the entire mouthparts are removed from the body. It is important that the tick is removed slowly because the mouthparts are covered in sharp, backward directed barbs which assist the tick in holding onto its host (Parsons et al. 1989). Sometimes, by removing the tick, a piece of the hosts skin may break off, which should not be a great concern, but bears watching for infection or later reaction.

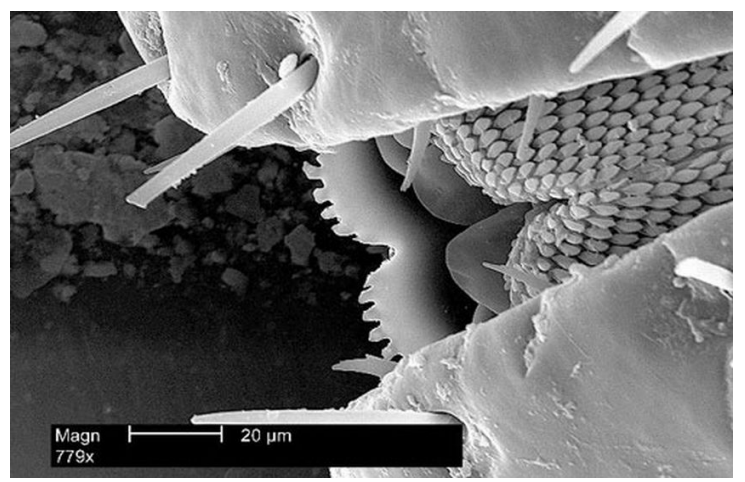

Figure 9. Enlarged view of the mouthparts of an American dog tick, Dermacentor variabilis (Say). Notice the hundreds of sharp, backward-directed barbs which assist the tick in holding onto its host. For an even closer look at these barbs see figure 10. Credits: Janice Carr, Center for Disease Control

To treat the wound, it is important to wash the area with soap and water followed by an antiseptic. Once the tick is removed, the recommendation is to save it in alcohol, with the date the tick was removed, in case it is needed for identification or pathogen

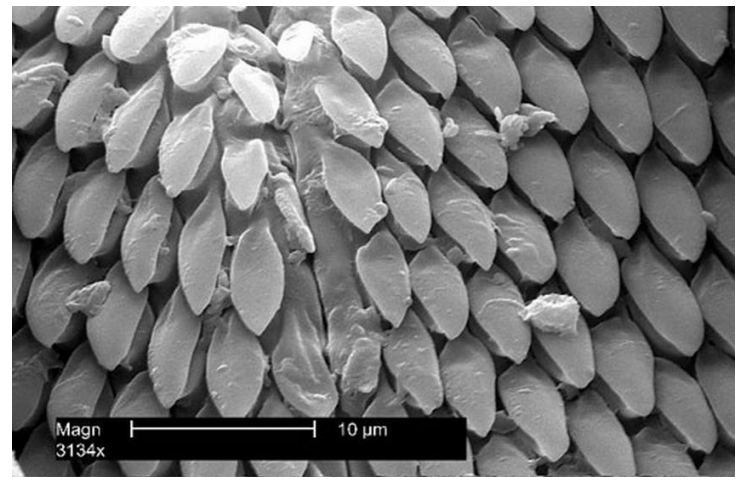

Figure 10. Enlarged view of the hundreds of sharp, backward-directed barbs on the mouthparts of an American dog tick, Dermacentor variabilis (Say). Credits: Janice Carr, Center for Disease Control

testing, should disease symptoms occur. If no symptoms occur within a month of removal, the tick may be discarded (USACHPPM 2003).

\section{Management}

The American dog tick occurs primarily in wooded, shrubby and long-grass areas. However, it is possible for residential areas to support populations of this tick. Shrubs, weeds, tall grass, clutter and debris on the property attracts the rodents that are hosts for immature ticks. By maintaining grass short, removing possible rodent harborages, and sealing cracks and crevices in and around the property one can directly reduce or prevent local tick populations. Keeping grass and weeds cut short decreases humidity, which helps kill ticks or makes an area undesirable for ticks and rodents. Additionally, it makes it difficult for ticks to climb on the vegetation and wait for its host. If pesticides are applied, cutting the vegetation short increases effectiveness and allows for better coverage. Removing rodent harborage areas may reduce an infestation.

Because dogs can easily pick up ticks while walking on infested grass or roaming through wooded areas, it is necessary to treat the pet properly. There are many products that can be applied to prevent or treat a tick infestation on an animal including topical treatments and sprays. Regularly grooming, washing bedding, and examining the dog are strongly recommended to prevent tick infestations. 
UF/IFAS Insect Management Guide for ticks http://edis.ifas.ufl.edu/IG088

\section{Selected References}

- American Lyme Disease Foundation (ALDF). (2006). Rocky Mountain spotted fever. http://www.aldf.com/RMSF.shtml (23 September 2008).

- Burg JG. 2001. Seasonal Activity and spatial distribution of host-seeking adults of the tick Dermacentor variabilis. Medical and Veterinary Entomology 15: 413-421.

- Campbel A. 1979. Ecology of the American dog tick, Dermacentor variabilis in southwestern Nova Scotia. Recent Advances in Acarology. Rodriguez JG (editor). Volume 2: 135-143.

- Carroll JF, Nichols JD. 1986. Parasitization of meadow voles, Microtus pennsylvanicus (Ord), by American dog ticks, Dermacentor variabilis (Say), and adult tick movement during high host density. Journal of Entomological Science 21: 102-113.

- Clark County Health District Office of Epidemiology (CCHDOE). (2001, May 11). Tularemia. http://www.southernnevadahealthdistrict.org/ physician/download/physician_tularemia.pdf (23 September 2008).

- Conlon JM, Rockett CL. 1982. Ecological investigations of the American dog tick, Dermacentor variabilis (Say), in northwest Ohio (Acari: Ixodidae). International Journal of Acarology 8: 125-131.

- Dame D, Fasulo TR. (2003). Public Health Pesticide Applicator Training Manual. http://vector.ifas.ufl.edu (23 September 2008).

- Goddard J. 1996. Physician's Guide to Arthropods of Medical Importance. pp. 287-302. CRC Press. Jackson, Mississippi.

- Gregson JD. 1973. Tick paralysis: an appraisal of natural and experimental data. Monograph No. 9. Canada Department of Agriculture, Ottawa.
- Eddis J, Oyston CF, Green M, Titball RW. 2002. Tularemia. Clinical Microbiology Reviews: 15: 631-646.

- Fasulo TR. (2002). Fleas and Ticks. Bug Tutorials http://pests.ifas.ufl.edu/software/det_bugs.htm. University of Florida/IFAS. CD-ROM. SW 159.

- Fasulo TR, Kern W, Koehler PG, Short DE. (2005). Pests In and Around the Home http://pests.ifas.ufl.edu/software/det_pests.htm. Version 2.0. University of Florida/IFAS. CD-ROM. SW 126.

- James M, Robert FH. 1969. Herm's Medical Entomology. 6th Edition. pp. 326-329. The Macmillan Company. Toronto, Ontario.

- Koehler PG, Oi F. (2003). Ticks. EDIS. http://edis.ifas.ufl.edu/IG088 (23 September 2008).

- Matheson R. 1950. Medical Entomology, 2nd Edition. Comstock Publishing Company, Inc. Ithaca, NY.

- McEnroe WD. 1979a. Dermacentor variabilis (Say) in eastern Massachusetts. Recent Advances in Acarology. Rodriguez JG (editor). Volume 2: 145-153.

- McEnroe, W.D. 1979b. The effect of the temperature regime on Dermacentor variabilis (Say) populations in eastern North America. Acarologia 20: 58-67.

- Mcnemee RB, Sames WJ, Maloney Jr FA. 2003. Occurrence of Dermacentor variabilis (Acari:Ixodidae) around a porcupine (Rodentia: Erthethizontidae) carcass at Camp Ripley, Minnesota. Journal of Medical Entomology 40: 108-111.

- Newhouse VF. (1983) Variations in population density, movement, and rickettsial infection rates in a local population of Dermacentor variabilis (Acarina: Ixodidae) ticks in the piedmont of Georgia. Environmental Entomology 12: 1737-1746. 
- Parsons GL, Rossignol PA. 1989. Identifying adult hard ticks commonly found on humans in Oregon. EM8410. Oregon State University Extension Service.

- Piesman J, Gage KL. 1996. Ticks and mites and the agents they transmit. The Biology of Disease Vectors. Beaty BJ, Marquardt WC (editors). pp. 160-174. University Press of Colorado. Newot, CO.

- Schmitt N. Bowner EJ, Gregson JD. 1969. Tick paralysis in British Columbia. Canadian Medical Association 100: 417-21.

- Smith EH, Whitman RC. 1992. Field Guide to Structural Pests. National Pest Management Association, Dunn Loring, VA.

- Sonenshine DE, Stout IJ. 1971. Ticks infesting medium-sized wild mammals in two forest localities in Virginia. Journal of Medical Entomology 8: 217-227.

- Thorner AR, Walker D, Petri WA. 1998. Rocky Mountain Spotted Fever. Clinical Infectious Diseases by the Infectious Diseases Society of America. 27: 1353-1360.

- U.S. Army Center for Health Promotion and Preventive Medicine (USACHPPM). 2003. Entomological Sciences Program. Aberdeen Proving Ground, MD 21010-5403. 